\title{
O papel da OIE no desenvolvimento do bem-estar animal
}

\author{
Cleandro Pazinato Dias \\ Membro do Grupo ad hoc da OIE em Bem-estar nos Sistemas Produtivos de Suínos
}

A Oficina Internacional de Epizootias (OIE) foi criada em 1924 com objetivo de evitar a disseminação de doenças dos animais a nível mundial. Em 2003, passou a adotar o nome de Organização Mundial de Saúde Animal, mantendo a abreviação OIE. Atualmente esta entidade intergovernamental congrega 181 países membros, oriundos de todos os continentes, sendo o Brasil um dos países signatários.

O papel da OIE no desenvolvimento e na promoção do bem-estar animal foi fortalecido a partir de 2001 por meio da adoção do tema como uma de suas prioridades nos planos estratégicos, além do reconhecimento de que a sanidade animal constitui componente chave do bem-estar animal. Animais saudáveis produzem alimentos de melhor qualidade, portanto, existe uma relação direta entre saúde, bem-estar e segurança alimentar.

0 conceito de bem-estar animal adotado em 2008 pela organização também contribuiu na compreensão do tema, a saber: o bem-estar significa a forma como o animal lida com o seu entorno. Um animal está em boas condições de bem-estar se estiver saudável, confortável, bem alimentado, seguro, em condições de expressar suas formas inatas de comportamento e se não estiver sofrendo dores, medo ou angústia. As boas condições de bem-estar exigem prevenção de enfermidades, administração e tratamentos veterinários apropriados, abrigo, alimentação, manejo e abate humanitário.

Para a promoção do bem-estar animal, a OIE desenvolve diretrizes a serem implantadas pelos estados membros, as quais são elaboradas para serem aplicáveis nos diferentes contextos socioeconômicos, culturais e religiosos; ou seja, são recomendações amplas e abrangentes. Os standards de bem-estar animal tratam da criação, transporte e abate dos animais. É importante salientar que as diretrizes da OIE são referência para a Organização Mundial de Comércio (OMC), estabelecendo padrões para o comércio internacional seguro. Na seção 7 do Código Sanitário dos Animais Terrestres da OIE, por exemplo, encontram-se 12 capítulos dedicados integralmente ao bem-estar animal. E, atualmente, estão em andamento o desenvolvimento de mais dois capítulos relativos ao bem-estar de galinhas poedeiras e suínos nas diferentes fases de produção. Todos estes documentos utilizam uma forte base científica e experiência prática, considerando o conceito de avaliação de indicadores de bem-estar obtidos diretamente dos animais. 